\title{
Tratamiento intravenoso inicial abreviado en 70 pacientes pediátricos con infecciones osteo-articulares
}

\author{
M. Alejandra Prado S., Macarena Lizama C., Anamaría Peña D., César Valenzuela M. y Tamara Viviani S.
}

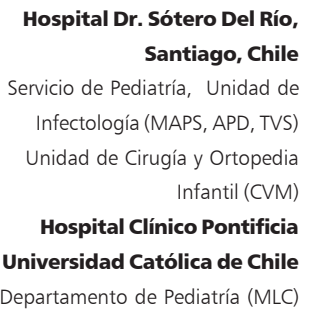

Recibido: 10 de julio de 2007 Aceptado: 22 de octubre de 2007

Los autores declaran

no tener conflictos de interés

Correspondencia a: María Alejandra Prado Sanhueza aleprados@gmail.com

\section{Short duration of initial intravenous treatment in 70 pediatric patients with osteoarticular infections}

Osteoarticular infections (OAI) are infrequent in pediatrics and there is controversy on the need for prolonged use of intravenous antimicrobials. Objective: To characterize and describe evolution and complications of a regimen of 7 days initial intravenous antibiotic treatment for OAI in children, completing 46 weeks of total treatment. Patients and methods: In a large pediatric hospital, 70 children younger than 15 years of age were diagnosed with OAI between March 2003 and December 2004. Children received 7 days of intravenous antibiotics followed by 3 to 5 weeks of oral treatment. Results: Incidence of OAI in this hospital was 1.8:10000. Patients mean age was $6.4 \pm 4.4$ years and $60 \%$ presented with septic arthritis, $36 \%$ osteomyelitis and $4 \%$ osteoarthritis. In $80 \%$ of cases, the infection was located in the lower extremity. Positive cultures were obtained in 59\% predominating Staphylococcus aureus (46.5\%). Seven patients had prolonged pain or persistantly high or increasing serum $\mathrm{C}$ reactive protein levels and were maintained on prolonged intravenous therapy. None of the 63 children with 7 day intravenous antimicrobials nor the 7 children with prolonged intravenous use developed a complication in the short-term follow up. Conclusions: Seven days of intravenous antibiotic for the initial phase of OAI treatment was effective in a majority of children and may be recommended.

Key words: Osteoarticular infections, osteomyelitis, septic arthritis, children, treatment.

Palabras clave: Infecciones osteo-articulares, osteomielitis, artritis séptica, niños tratamiento.

\section{Introducción}

$\mathrm{L}$ as infecciones osteo-articulares (IOA) son una patología poco frecuente en pediatría, con una incidencia de 1: 1.000 a 1: 20.000 individuos para osteomielitis (OM) y 5,5 a 12: 100.000 para artritis séptica (AR). La mayoría de los niños con IOA tiene un resultado favorable; sin embargo, el diagnóstico tardío puede llevar a complicaciones hasta en 12\% de los $\operatorname{casos}^{1-4}$.

Existe consenso en que el tratamiento antimicrobiano empírico inicial debe efectuarse por vía endovenosa (ev), en forma precoz y dirigido, principalmente, a erradicar microorganismos adquiridos por bacteriemia ${ }^{7-13}$. Sin embargo, existe controversia en torno a cuántos días este tratamiento deba ser administrado por vía ev y el tiempo total de la antibioterapia. En la literatura se ha sugerido un rango entre 3 y 6 semanas de tratamiento total ${ }^{6,14} \mathrm{y}$ hay evidencia histórica de que el tratamiento por menos de tres semanas se ha asociado con una mayor frecuencia de recaída y recurrencia ${ }^{15}$. El tiempo de tratamiento ev es controvertido, con proto- colos que varían desde ninguna, hasta seis semanas $^{3,16-18}$. En nuestro hospital, históricamente se había usado tratamiento por plazo total de 4 a 6 semanas, incluyendo una fase inicial ev de 14 a 21 días.

El objetivo de este estudio es caracterizar niños con IOA consultantes en un centro hospitalario de Santiago, Chile, describir su evolución y frecuencia de complicaciones al acortar el tiempo de tratamiento endovenoso a 7 días, seguido de terapia antibiótica per os (p.o.), enterando 4 a 6 semanas de tratamiento total.

\section{Pacientes y Métodos}

Estudio descriptivo de IOA en pacientes pediátricos consultantes en el hospital público Sótero del Río, institución con alto nivel de complejidad, ubicada en el área sur-oriente de Santiago, Chile, cuya población asignada es de 1.015.943 habitantes, de los cuales 288.386 son niños bajo 15 años de edad y 151.094 son varones.

Definición de IOA: Infección supurativa del hueso 
y/o articulación, con historia de dolor, fiebre y pérdida de la función, confirmada por el aspecto macroscópico del hueso o del líquido articular, durante la cirugía y/o mediante el hallazgo de cultivo positivo del líquido articular o tejido óseo.

Se clasificaron las IOA como AS si había sólo infección articular, OM en los casos en que estaba afectado el tejido óseo, y osteoartritis (OA) si estaban comprometidos la articulación y el tejido óseo contiguo en forma simultánea.

Criterios de inclusión: Fueron incluidos todos los pacientes entre dos meses y 14 años 11 meses de edad, con diagnóstico de IOA, hospitalizados entre marzo del año 2003 y diciembre de 2004.

Criterios de exclusión: Pacientes inmunocomprometidos, IOA asociadas a fractura expuesta o daño en la piel, o demostración de enfermedad del tejido conectivo que debuta como mono o poliartritis. No se excluyeron niños con enfermedades crónicas, aquellos con IOA múltiple simultánea, o aquellos que habían recibido antibioterapia previa.

Intervención: Todos los pacientes fueron sometidos a procedimientos quirúrgicos, durante los cuales se obtuvo muestras de tejido óseo y/o líquido articular, que fueron sembrados en medios de cultivo sólidos o en botellas de hemocultivos. Estas muestras se enviaron al laboratorio de microbiología del mismo hospital.

Los pacientes recibieron terapia antimicrobiana ev durante, al menos, siete días, seguida de antimicrobianos p.o., para completar seis semanas en los casos de OM, OA y AS de la cadera, o un total de cuatro semanas en los casos de AS localizadas en articulaciones distintas de la cadera. La elección de la terapia antimicrobiana inicial fue de acuerdo con la edad del niño: entre dos meses y cinco años, se usó cloxacilina asociada a ceftriaxona; y a partir de los seis años de edad, se administró cloxacilina y un aminoglucósido. El tratamiento antimicrobiano se ajustó, según la susceptibilidad in vitro, una vez que el agente etiológico fue identificado. En los casos con cultivo negativo, el tratamiento ev inicial se continuó igual y se cambió al $8^{\circ}$ día a: cloxacilina p.o. y cloranfenicol en pacientes bajo seis años de edad y a cloxacilina sola en pacientes sobre esa edad. Los requisitos para cambiar de tratamiento ev a p.o. fueron: que el paciente estuviera afebril por más de 48 horas y que hubiera disminución significativa de la PCR. Se realizó seguimiento ambulatorio semanal en la policlínica de Enfermedades Infecciosas Pediátricas en el mismo hospital, hasta finalizar el tratamiento antimicrobiano.
Registro de datos: En un formulario ad-hoc, se registraron, en forma prospectiva, datos bio-demográficos, localización de la infección y tipo de IOA.

Al momento del ingreso hospitalario se registró el recuento de leucocitos y PCR en todos los pacientes, considerándose leucocitosis aquel recuento $\geq 15.000$ céls $/ \mathrm{mm}^{3}$ y PCR elevada aquella $\geq 40 \mathrm{mg} / \mathrm{L}$.

Fueron registrados los resultados de cultivos, días de hospitalización, régimen y tiempo de tratamiento antimicrobiano ev y si éste fue modificado durante la evolución. Además, se registró el tiempo de tratamiento p.o. Fueron evaluados diariamente el dolor, la $\mathrm{T}^{\mathrm{o}} \mathrm{e}$ impotencia funcional durante la hospitalización y en forma semanal, en la fase de terapia oral. En caso de evolución clínica desfavorable o PCR inicial elevada, se controló este parámetro en forma repetida durante la evolución.

El análisis estadístico de variables categóricas, fue realizado con prueba de $\chi^{2}$ o prueba exacta de Fischer. Para comparar variables continuas, se usó la prueba no paramétrica de Mann-Whitney. Los valores se expresaron como promedio \pm DS, a menos que se especifique otro valor. Se consideró significativo un valor $\mathrm{p}<0,05$.

\section{Resultados}

Pacientes. Durante el período del estudio fueron ingresados 70 pacientes, 18 en el año 2003 y 52 en el 2004. La incidencia para el año 2004 fue estimada en 1,8:10.000 niños bajo 15 años de edad, con un promedio de 38 casos nuevos al año. Del total, 36 eran de sexo masculino (51\%), con una incidencia por género de 2: 10.000 para los varones y de 1,6: 10.000 para las mujeres. La incidencia, de acuerdo con el tipo de IOA, fue de 1,1 para AS y 0,5 para OM por cada 10.000 personas bajo 15 años. La caracterización de los pacientes según tipo de IOA se resume en la Tabla 1. Las IOA se distribuyeron a través de todo el año, con una mayor frecuencia durante los meses de primavera y verano (Figura 1).

Localizaciones. Las articulaciones más frecuentemente afectadas fueron cadera y rodilla, mientras que la tibia y el fémur fueron los sitios predominantes en OM. Las OA se localizaron en tobillo-peroné y caderafémur (Tabla 2).

Análisis de laboratorio. La PCR de ingreso se obtuvo en 67 pacientes y fue elevada en $70 \%$, con un valor promedio de $90 \pm 71 \mathrm{mg} / \mathrm{L}$ (rango: $0-293 \mathrm{mg} / \mathrm{L}$ ). Cuarenta por ciento de los pacientes tenía leucocitosis al ingreso, el recuento promedio fue de $14.250 \pm 6.307$ 


\begin{tabular}{|c|c|c|c|c|}
\hline & Total & AS & OA & OM \\
\hline $\mathrm{N}$ & 70 & 42 & 3 & 25 \\
\hline Hombres & $36(51,4 \%)$ & $21(50 \%)$ & $3(100 \%)$ & $12(48 \%)$ \\
\hline Promedio edad \pm DS (años) & $6,4 \pm 4,4$ & $5,3^{*} \pm 4,5$ & $4 \pm 1,7$ & $8,3^{*} \pm 3,7$ \\
\hline \multicolumn{5}{|l|}{ Parámetros de laboratorio } \\
\hline Cultivo positivo & $40 / 68$ (59 \%) & $18 / 40(45 \% *)$ & $3 / 3(100 \%)$ & $19 / 25(76 \% *)$ \\
\hline \multicolumn{5}{|l|}{$P C R$} \\
\hline Promedio \pm DS (mg/L) & $90 \pm 71$ & $95 \pm 68$ & $80 \pm 14$ & $84 \pm 82$ \\
\hline Rango (mg/L) & $0-293$ & $1-293$ & $71-96$ & $0-284$ \\
\hline \multicolumn{5}{|l|}{ Leucocitos $/ \mathrm{mm}^{3}$} \\
\hline Promedio \pm DS & $14.250 \pm 6.307$ & $15.297 \pm 7.068$ & $15.933 \pm 2.638$ & $12.295 \pm 4.750$ \\
\hline Rango & $4.600-38.300$ & $4.600-38.300$ & $12.900-17.700$ & $7.000-23.800$ \\
\hline \multicolumn{5}{|l|}{ Evolución } \\
\hline \multicolumn{5}{|l|}{ Días de hospitalización } \\
\hline Promedio \pm DS (días) & $8,6 \pm 2,9$ & $8,5 \pm 3,1$ & $8,6 \pm 0,5$ & $8,6 \pm 2,7$ \\
\hline Rango (días) & $5-19$ & $5-19$ & $8-9$ & $5-16$ \\
\hline Mediana (días) & 8 & 7,5 & 9 & 8 \\
\hline Complicaciones menores & $6(8,6 \%)$ & $6(14,3 \%)$ & 0 & 0 \\
\hline
\end{tabular}

céls/mm³ (rango: 4.600 - 38.300 céls $/ \mathrm{mm}^{3}$ ) (Tabla 1). Se realizó cultivo de tejido óseo y/o líquido articular en todos los pacientes, excepto dos, que presentaban compromiso sacro-ilíaco. De todos los cultivos obtenidos, 40 fueron positivos (59\%) (Tabla 3). En 20 niños se aisló Staphylococcus aureus, sólo tres de ellos

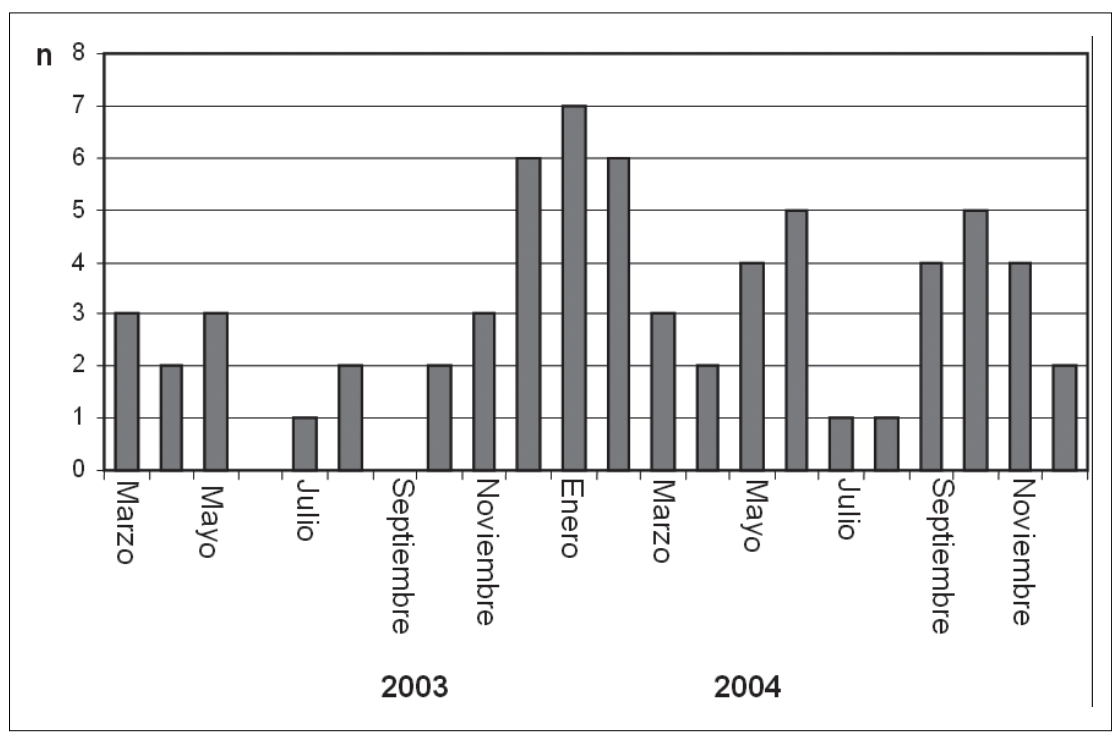

Figura 1. Distribución mensual de infecciones osteo-articulares. tenían menos de seis años. El segundo agente etiológico más frecuentemente aislado fue Streptococcus pyogenes, que se presentó a todas las edades, con predominancia en el grupo bajo 6 años de edad (Figura 2).

Tratamiento. De los 32 niños bajo 6 años, 31 recibieron cloxacilina combinada con ceftriaxona, ajustándose la terapia antimicrobiana de acuerdo con los resultados del cultivo. En un paciente se inició tratamiento con penicilina más clindamicina debido a la sospecha de infección por $S$. pyogenes, la cual fue más tarde confirmada por cultivo. De los 38 pacientes sobre 6 años, 34 iniciaron tratamiento con cloxacilina más aminoglucósido, mientras que en cuatro el esquema anti-infeccioso fue diferente: uno recibió penicilina más clindamicina por sospecharse una infección por $S$. pyogenes, otro recibió vancomicina y ciprofloxacina por reciente infección por S. pneumoniae resistente a penicilina, aislándose $S$. aureus resistente a meticilina adquirido en el hospital, un tercero recibió cloxacilina combinado con cloranfenicol debido a infección de la articulación sacro-ilíaca, y el cuarto recibió cloxacilina y penicilina por infección del hueso calcáneo. Ocho pacientes (11\%) recibieron 10 o más días de tratamiento antimicrobiano ev: dos debido a infección simultánea de dos articulaciones, con dolor persistente en uno de ellos; un paciente con OM causada por Pseudomonas sp; tres por dolor persistente; y dos 
debido a aumento de PCR en el seguimiento. No consideramos mayor extensión del tratamiento anti-infeccioso ev en aquellos niños que lo recibieron 8 ó 9 días, ya que la mayoría fue porque cumplían siete días en fin de semana o feriado y no se les cambió la vía de administración hasta el siguiente día hábil.

Evolución y seguimiento. La estadía hospitalaria promedio fue de 8,6 días (Tabla 1). Siete pacientes (10\%) se perdieron de seguimiento ambulatorio. De 63 niños con seguimiento completo, 56 tuvieron un resultado favorable (89\%), sin dolor, fiebre más allá de 24 horas post cirugía ni impotencia funcional; mientras que cuatro tuvieron dolor persistente en el corto plazo, dos presentaron elevación o persistencia de PCR elevada y uno tuvo dolor y persistencia de PCR elevada (Tabla 4). De los pacientes con dolor persistente, uno de ellos requirió re-hospitalización para tratamiento del dolor (paciente 1), otro (paciente 2) luego de 42 días de tratamiento con vancomicina-ciprofloxacina para infección por $S$. aureus resistente a meticilina, seguía con dolor al movilizar la cadera derecha, PCR elevada y VHS 54 mm/hr. El cintigrama óseo mostró persistencia de captación en la cadera, motivando a extender la antibioterapia por dos semanas más, con buena evolución clínica y regresión de los parámetros inflamatorios. En otros dos (pacientes 3 y 4) el dolor cedió antes del alta hospitalaria. En los dos pacientes

\begin{tabular}{|c|c|c|}
\hline & $n$ & $\%$ \\
\hline Artritis séptica & 42 & \\
\hline Extremidad inferior & 31 & 74 * \\
\hline Extremidad superior & 8 & 19 * \\
\hline Cadera & 13 & 31 \\
\hline Rodilla & 12 & 28,6 \\
\hline Hombro & 4 & \\
\hline Tobillo & 4 & \\
\hline Sacro-ilíaca & 3 & \\
\hline Muñeca & 3 & \\
\hline Cadera y rodilla & 2 & \\
\hline Codo & 1 & \\
\hline Osteoartritis & 3 & \\
\hline Tobillo-peroné & 2 & \\
\hline Cadera-fémur & 1 & \\
\hline Osteomielitis & 25 & \\
\hline Extremidad inferior & 22 & 88 * \\
\hline Extremidad superior & 3 & 12 * \\
\hline Tibia & 6 & 24 \\
\hline Fémur & 5 & 20 \\
\hline Metatarso & 5 & 20 \\
\hline Antebrazo (radio o húmero) & 3 & \\
\hline Calcáneo & 2 & \\
\hline Peroné & 2 & \\
\hline Ortejo & 2 & \\
\hline * Valor $p=0,02$. Extremidad & 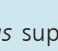 & \\
\hline
\end{tabular}

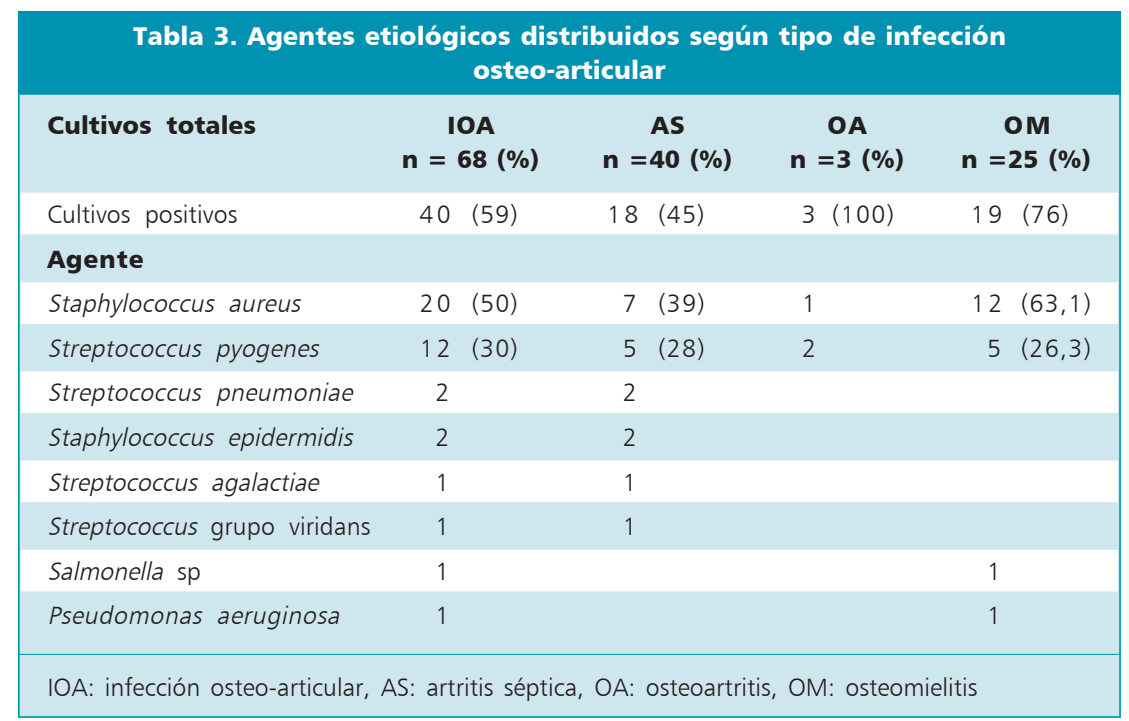

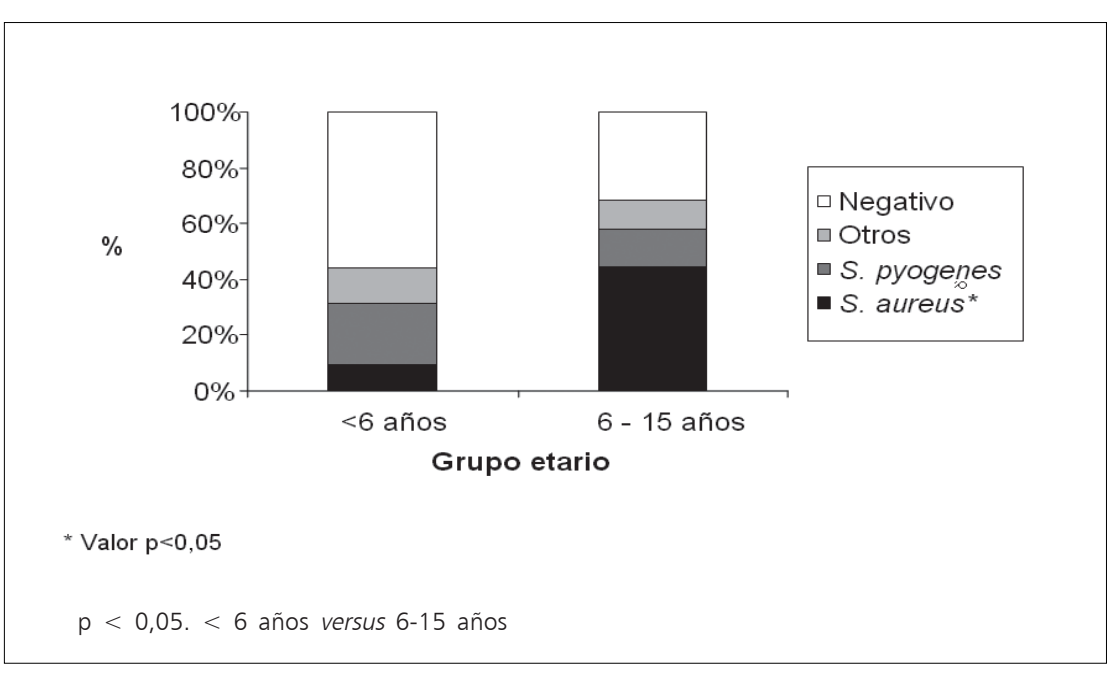

Figura 2. Agente etiológico según grupo etario. * Valor $p<0,05$ 


\begin{tabular}{|c|c|c|c|c|c|c|c|}
\hline & Paciente 1 & Paciente 2 & Paciente 3 & Paciente 4 & Paciente 5 & Paciente 6 & Paciente 7 \\
\hline Edad (años) & 7 & 7 & 12 & 11 & 5 & 0,7 & 13 \\
\hline Sexo & $\mathrm{F}$ & $\mathrm{F}$ & $\mathrm{F}$ & $\mathrm{F}$ & $\mathrm{F}$ & $\mathrm{F}$ & $\mathrm{F}$ \\
\hline Tipo de IOA & AS & AS & AS & AS & AS & AS & AS \\
\hline Localización & Cadera-tobillo & Cadera & Sacro-ilíaca & Muñeca & Codo & Cadera & Sacro-ilíaca \\
\hline Agente aislado & S. pyogenes & S. aureus MR & No se hizo cultivo & S. pyogenes & S. pyogenes & S. pneumoniae & $\begin{array}{l}\text { No se hizo } \\
\text { cultivo }\end{array}$ \\
\hline Evolución & Dolor & Dolor & Dolor & Dolor & $\begin{array}{l}\text { Persistencia de } \\
\text { PCR elevada }\end{array}$ & $\begin{array}{l}\text { Persistencia de } \\
\text { PCR elevada }\end{array}$ & $\begin{array}{l}\text { Dolor y } \\
\text { persistencia } \\
\text { de PCR elevada }\end{array}$ \\
\hline Días de hospitalización & $17+7$ & $3 *$ & 10 & 16 & 19 & 9 & 18 \\
\hline Tratamiento ev /total (d) & $14 / 42$ & $42+14 / 42+14$ & $7 / 46$ & $13 / 39$ & $18 / 42$ & $10 / 41$ & $10 / 44$ \\
\hline Leucocitos/ mm³ & 28.700 & 12.300 & 14.400 & 38.300 & 11.100 & 16.000 & 9.800 \\
\hline PCR (mg/L) & $\begin{array}{l}192 / 124 / 68 / \\
82 / 29\end{array}$ & $96 / 14 / 5$ & $150 / 10 / 8$ & $293 / 28$ & $\begin{array}{l}134 / 164 / 40 / \\
77 / 35,5\end{array}$ & $\begin{array}{l}29 / 65 / 51 / \\
10\end{array}$ & $\begin{array}{l}184 / 172 / 69 / \\
82 / 32 / 3\end{array}$ \\
\hline
\end{tabular}

que tuvieron elevación o persistencia de PCR elevada, fue necesario prolongar la antibioterapia (pacientes 5 y 6); uno de ellos, con AS de codo, requirió reintervención quirúrgica en el día 14 de antimicrobianos ev por persistencia del compromiso articular y PCR en ascenso. El paciente 7, además de dolor persistente, evolucionó con PCR elevada, lo que hizo extender el tratamiento ev y la hospitalización.

\section{Discusión}

En la población estudiada, la incidencia de IOA fue de 1,8:10.000 niños bajo 15 años de edad, cifra comparable a las descritas con anterioridad ${ }^{1-3}$. Se observó un menor número de casos durante el año 2003, comparado con el 2004, lo que puede atribuirse a que el inicio del estudio fue en marzo de 2003. La AS fue más frecuente que la OM, hecho descrito previamente ${ }^{11}$. La incidencia fue similar en ambos géneros, otros trabajos encontraron una mayor frecuencia en hombres ${ }^{19}$. Las IOA en este estudio fueron detectadas a toda edad, sin predominancia de algún grupo etario; sin embargo, el promedio de edad en los pacientes con AS fue significativamente menor que en aquellos con OM. Se observó una tendencia estacional, un mayor número de pacientes fue afectado durante los meses de primavera y verano, lo que pudiera estar relacionado con un aumento en la actividad física durante ese período del año y una posible asociación entre trauma y mayor predisposición a IOA. En la mayoría de los pacientes, la infección ocurrió en grandes articulaciones de extremidades inferiores y huesos largos comúnmente expuestos a traumatismos, apoyando la teoría patogénica para las IOA de que el trauma favorece la focalización en el aparato locomotor en el curso de una bacteriemia ${ }^{8,19,20,23,24}$.

En las IOA, usualmente existe elevación de parámetros inflamatorios como leucocitosis y $\mathrm{PCR}^{8,20-22,24}$, lo que también fue observado en esta ocasión. La PCR estuvo elevada en la mayoría de los casos, mientras la leucocitosis estuvo presente en menos de la mitad de los casos; series previas ${ }^{20-22}$ ya destacaron que la leucocitosis no es un indicador sensible de IOA. Otros estudios han descrito VHS persistentemente elevada en el período agudo de la $\mathrm{IOA}^{8,20-22,24}$; en el nuestro, la VHS no fue evaluada en todos los pacientes.

En series previas, se logró establecer el diagnóstico microbiológico de la IOA hasta en $64 \%$ de los pacientes $^{25-27}$. En esta serie, 59\% de los cultivos fueron positivos, con un significativo mejor rendimiento en muestras de OM, lo que probablemente es debido a que el tejido óseo es una mejor muestra para cultivar que el líquido sinovial, como fuera ratificado por García y cols $^{27}$. El agente causal más encontrado fue $S$. aureus, hallazgo ampliamente descrito ${ }^{3,8,11,19-21,24,28,29}$. Confirmamos, además, resultados de Sonnen ${ }^{19}$ y Bonhoeffer ${ }^{20}$, quienes observaron predominio de $S$. aureus en pacientes sobre seis años de edad, no así bajo esa edad, grupo en que $S$. aureus fue aislado sólo en $9 \%$ de los 
casos. Welkon publicó en $1986^{26}$, que $46 \%$ de las AS fueron causadas por Haemophilus influenzae tipo b (Hib). Desde la introducción de la vacuna contra Hib, este agente infeccioso ha disminuido en forma significativa como causal de $\mathrm{IOA}^{10,29-31}$, siendo la probable razón por la que no se aisló Hib en nuestra serie. Staphylococcus aureus resistente a meticilina, aislado en una niña hospitalizada, sigue siendo, aún, un microorganismo intrahospitalario en nuestro medio, a diferencia de otros países, donde puede ser adquirido en la comunidad ${ }^{32,33}$.

El total de días de tratamiento es un tema controversial, la tendencia actual es acortar los días de tratamiento $\mathrm{ev}^{18}$. Antes de este estudio, en nuestro centro se utilizaba el protocolo de tratamiento ev prolongado (14 a 21 días); los resultados exhibidos permitieron disminuir los días de terapia ev a siete días. El cambio precoz de tratamiento ev a p.o. acorta los días de hospitalización y sus costos, favorece el bienestar del paciente y reduce el riesgo de infecciones nosocomiales y aquellas asociadas a terapia ev prolongada ${ }^{12,18,34-36}$. A pesar de lo anterior, es importante considerar la adherencia y tolerancia a la terapia p.o. antes de decidir el alta hospitalaria de cada paciente ${ }^{37}$.

No hubo complicaciones mayores en el corto plazo. Cinco pacientes manifestaron dolor persistente en el seguimiento, dos de ellos con compromiso sacro-ilíaco, articulación de difícil acceso para efectuar un drenaje y aseo quirúrgico. Un factor, observado en tres pacientes que evolucionaron en forma poco satisfactoria, fue una demora significativa entre el diagnóstico y el inicio de tratamiento antimicrobiano, lo que pudiera entrañar riesgo de complicaciones; Welkton ${ }^{26}$ describió que el retraso de cuatro días en el inicio del tratamiento anti-infeccioso se asocia con una mayor frecuencia de complicaciones.

Esta experiencia clínica tiene algunas limitaciones. En la evaluación de ingreso en todo paciente, no se midió el valor de la VHS. Por otra parte, la pérdida de pacientes en el seguimiento ambulatorio no fue significativa (10\%). Finalmente, en esta serie, $41 \%$ de los cultivos fueron negativos, un tercio de ellos fue realizado en medio de cultivo sólido y mantenidos en incubación durante 48 horas, método de menor rendimiento, especialmente para agentes fastidiosos que requieren de medios de cultivo enriquecidos y mayor tiempo de incubación; este hecho pudiera explicar la ausencia de agentes fastidiosos como Kingella kingae en este serie, la que ha sido identificada cada vez con mayor frecuencia ${ }^{28,38}$. Por lo anterior, sugerimos que las muestras de líquido sinovial y tejido óseo, sean sembradas en botellas de hemocultivo, como una manera de optimizar el rendimiento de los cultivos. Teniendo en consideración que las IOA en pediatría son, en su mayoría, secundarias a bacteriemia, el hemocultivo es una herramienta adicional a los cultivos óseo y de líquido articular en la búsqueda etiológica en IOA.

En suma, nuestros resultados sugieren que un régimen inicial de tratamiento antimicrobiano ev durante siete días, seguido de tratamiento p.o. para completar cuatro a seis semanas de terapia total, es un esquema seguro, sin complicaciones mayores en el corto plazo. Es necesario realizar estudios multicéntricos, prospectivos y randomizados, que comparen tiempos de terapias abreviada con la convencional y un seguimiento a largo plazo, de manera de determinar eventuales factores de inadecuada respuesta terapéutica.

Agradecimientos. A Cristina Guajardo, Enfermera Universitaria, Policlínica de Enfermedades Infecciosas Pediátricas, Hospital Sótero Del Río. A Paola Viviani, matemática estadística, Centro de Investigaciones Médicas, Escuela de Medicina, Pontificia Universidad Católica de Chile, por el apoyo en el análisis estadístico.

\section{Resumen}

Las infecciones osteo-articulares (IOA) son poco frecuentes en pediatría. Existe controversia acerca de la óptima duración y la vía de administración de la terapia antimicrobiana. Objetivo: Caracterizar y describir la evolución y complicaciones en niños con IOA que recibieron 7 días iniciales de terapia endovenosa, completando 4 a 6 semanas de terapia total. Pacientes y Métodos: Estudio descriptivo, que incluyó a 70 niños con diagnóstico de IOA, entre marzo de 2003 y diciembre de 2004 en un hospital pediátrico, quienes recibieron tratamiento endovenoso abreviado a 7 días, seguido de terapia oral por 3 a 5 semanas. Resultados: La incidencia de IOA fue de 1,8: 10.000 niños bajo 15 años de edad. El promedio de edad fue 6,4 \pm 4,4 años. Sesenta por ciento presentaba artritis séptica, 36\% osteomielitis y 4\% osteoartritis. En 80\% la infección se localizó en extremidades inferiores. Los cultivos fueron positivos en 59\%. En $46,5 \%$ se aisló Staphylococcus aureus. Siete niños evolucionaron con dolor persistente o elevación significativa de PCR y requirieron prolongar la terapia endovenosa y/o total, sin presentar complicaciones a corto plazo. Conclusiones: Siete días de terapia antimicrobiana intravenosa parece ser efectivo y recomendable para el tratamiento, en su fase inicial, de las infecciones osteo-articulares. 


\section{Referencias}

1.- Christiansen P, Frederiksen B, Glazowski J, Scavenius M, Knudsen F U. Epidemiologic, bacteriologic, and long-term follow-up data of children with acute hematogenous osteomyelitis and septic arthritis: a ten-year review. J Pediatr Orthop B 1999; 8: 302-5.

2.- Karwowska A, Davies H D, Jadavji T. Epidemiology and outcome of osteomyelitis in the era of sequential intravenous-oral therapy. Pediatr Infect Dis J 1998; 17: 1021-6.

3.- Blyth M J G, Kincaid R, Craigen M A C, Bennet G C. The changing epidemiology of acute and subacute haematogenous osteomyelitis in children. J Bone Joint Surg [Br] 2001; 83-B: 99-102.

4.- Krogstad P. Osteomyelitis and Septic Arthritis. In: Feigin R D, Cherry J D, Demmler G J, Kaplan S L. Textbook of Pediatric Infectious Diseases. Fifth edition. Philadelphia. Saunders 2004: 713-36.

5.- Paluska S A. Osteomyelitis. Clin Family Pract 2004; 6: 127-56.

6.- Dirschl D R, Almekinders L C. Osteomyelitis. Common causes and treatment recommendations. Drugs 1993; 45: 29-43.

7.- Nelson J D. Acute osteomyelitis in children. Infect Dis Clin North Am 1990; 4: 513-22.

8.- Kao H, Huang Y, Chiu Ch, Chang L, Lee Z, Chung $\mathrm{P}$, et al. Acute hematogenous osteomyelitis and septic arthritis in children. J Microbiol Immunol Infect 2003; 36: 260-5.

9.- Corti N, Sennhauser F H, Stauffer U G, Nadal D. Fosfomycin for the initial treatment of acute haematogenous osteomyelitis. Arch Dis Child 2003; 88: 512-6.

10.- Floyed R, Steele R. Culture-negative osteomyelitis. Pediatr Infect Dis J 2003; 22: 731-5.

11.- Craigen M A C, Watters J, Hackett J S. The changing epidemiology of osteomyelitis in children. J Bone Joint Surg 1992; 74-B (4): 541-5.

12.- Shetty A K, Gedalia A. Management of septic arthritis. Indian J Pediatr 2004; 71: 819-24.

13.- Lazzarini L, Mader J T, Calhoun J H. Osteomyelitis in long bones. J Bone Joint Surg Am 2004; 86: 2305-18.

14.- Prober C G. Current antibiotic therapy of community-acquired bacterial infections in hospitalized children: bone and joint infections. Pediatr Infect Dis J 1992; 11: $156-9$.
15.- Dich V Q, Nelson J D, Haltalin K C. Osteomyelitis in infants and children. A review of 163 cases. Amer J Dis Child 1975; 129: 1273-8.

16.- Le Saux N, Howard A, Barrowman N J, Gaboury I, Sampson M, Moher D. Shorter courses of parenteral antibiotic therapy do not appear to influence response rates for children with acute hematogenous osteomyelitis: a systemic review. BMC Infect Dis 2002; 2: 16-24.

17.- Jaberi F M, Shahcheraghi G H, Ahadzadeh M. Short-term intravenous antibiotic treatment of acute hematogenous bone and joint infection in children: a prospective randomized trial. J Pediatr Orthop 2002; 22: 317-20.

18.- Daver N G, Shelburne S A, Atmar R L, Giordano T P, Stager C E, Reitman C A, et al. Oral step-down therapy is comparable to intravenous therapy for Staphylococcus aureus osteomyelitis. J Infect 2007; 54: 539-44.

19.- Sonnen G M, Henry N K. Pediatric bone and joint infections. Diagnosis and antimicrobial management. Pediatr Clin North Am 1996; 43: 933-47.

20.- Bonhoeffer J, Haeberle B, Schaad U B, Heininger U. Diagnosis of acute haematogenous osteomyelitis and septic arthritis: 20 years experience at the University Children's Hospital Basel. Swiss Med Wkly 2001; 131: 575-81.

21.- Unkila-Kallio L, Kallio M J T, Eskola J, Peltola H. Serum C-reactive protein, erythrocyte sedimentation rate, and white blood cell count in acute hematogenous osteomyelitis of children. Pediatrics 1994; 93: 59-62.

22.- Roine I, Faingezicht I, Arguedas A, Herrera J F, Rodríguez F. Serial serum C-reactive protein to monitor recovery from acute hematogenous osteomyelitis in children. Pediatr Infect Dis J 1995; 14: 40-4.

23.- Bradley J S, Kaplan S L, Tan T Q, Barson WJ, Arditi M, Schutze G E, et al and The Pediatric Multicenter Pneumococcal Surveillance Study Group. Pediatric pneumococcal bone and joint infections. Pediatrics 1998; 102: 1376-82.

24.- Yuan H C, Wu K G, Chen C J, Tang R B, Hwang B T. Characteristics and outcome of septic arthritis in children. J Microbiol Immunol Infect 2006; 39: 342-7.

25.- Dagan R. Management of acute hematogenous osteomyelitis and septic arthritis in the pediatric patient. Pediatr Infect Dis J 1993; 12: 88-93.
26.- Welkon C J, Long S S, Fisher M C, Alburger P D. Pyogenic arthritis in infants and children: a review of 95 cases. Pediatr Infect Dis J 1986; 5: 669-76.

27.- García P, Irribarra L, Ramirez V, Cervilla V, De la Barra R, Montiel F, et al. The yield of the microbiological study in the osteoarticular infection. Rev Chil Infectol 2000; 17: 101-8.

28. - Moumile K, Merckx J, Glorion C, Pouliquen J C, Berche P, Ferroni A Bacterial aetiology of acute osteoarticular infections in children. Acta Paediatr 2005; 94: 419-22.

29.- Goergens E D, McEvoy A, Watson M, Barrett I R. Acute osteomyelitis and septic arthritis in children. J Paediatr Child Health 2005; 41: 59-62.

30.- Bowerman S G, Green N E, Menico G A. Decline of bone and joint infections attributable to $H$. influenzae type b. Clin Orthop Relat R 1997; 341: 128-33.

31.- Howard A W, Viskontas D, Sabbagh C. Reduction in osteomyelitis and septic arthritis related to $H$. influenzae type b vaccination. J Pediatr Orthop 1999; 19: 705-9.

32.- Martínez-Aguilar G, Avalos-Mishaan A, Hulten K, Hammerman W, Mason Jr E O, Kaplan S L. Community-acquired, methicillin-resistant and methicillinsusceptible Staphylococcus aureus musculoskeletal infections in children. Pediatr Infect Dis J 2004; 23: 701-6.

33.- Arnold S R, Elías D, Buckingham S C, Thomas E D, Novais E, Arkader A, et al. Changing patterns of acute hematogenous osteomyelitis and septic arthritis: emergence of community-associated methicillinresistant Staphylococcus aureus. J Pediatr Orthop 2006; 26: 703-8.

34.- Peltola H, Unkila-Kallio L, Kallio M and the Finnish Study Group. Simplified treatment of acute staphylococcal osteomyelitis of childhood. Pediatrics 1997; 99: 846-50

35.- Nelson J D. Options for outpatient management of serious infections. Pediatr Infect Dis J 1992; 11: 175-8.

36.- Newton P O, Ballock T, Bradley J S. Oral antibiotic therapy of bacterial arthritis. Pediatr Infect Dis J. 1999; 18: 1102-3

37.- Syrogiannopoulos G A, Nelson J D. Duration of antimicrobial therapy for acute suppurative osteoarticular infections. Lancet 1998; 1(8575-6): 37-40.

38.- Saphyakhajon P, Greene G. Kingella kingae: an emerging pathogen of acute osteoarticular infections in children. Pediatrics 2006; 117: 249. 